\title{
ANALISIS KEPUASAN DAN LOYALITAS WISATAWAN MENGUNJUNGI DESTINASI WISATA PULAU HARAPAN DI KEPULAUAN SERIBU JAKARTA
}

\author{
Uuh Sukaesih', Miswan ${ }^{2}$ \\ Prodi Manajemen, Fakultas Ekonomi dan Bisnis, Universitas Sahid Jakarta \\ Jl. Prof. Soepomo No 84, Tebet, Jakarta Selatan \\ Email korespondensi : sukaesihuuh@yahoo.co.id
}

\begin{abstract}
ABSTRAK
Pemerintah Kabupaten Administrasi Kepulauan Seribu telah mendukung pengembangan pariwisata di pulau Pulau Kelapa di Kepulauan Seribu. Hal tersebut dapat dilihat dari usaha pemerintah dalam menyediakan fasilitas serta sarana dan prasarana penunjang pariwisata untuk mengembangkan Kepulauan Seribu sebagai daerah tujuan wisata. Tujuan dari penelitian ini adalah adalah : Untuk mengetahui Kepuasan dan loyalitas wisatawan yang mengujungi Destinasi Wisata Pulau Harapan di Kepulauan Seribu Jakarta. Penelitianakan dilakukan dengan menyebarkan kuesioner kepada 100 orang (menggunakan rumus Slovin) yang sudah mengunjungi objek wisata Pulau Harapan di Kepulauan Seribu Jakarta. Metode analisis dilakukan dengan analisis deskriptif, yaitu dengan mendeskriptifkan atau menggambarkan tentang hasil dari penelitian mengenai kepuasan dan loyalitas wisatawan yang mengujungi Destinasi Wisata Pulau Kelapa di Kepulauan Seribu Jakarta dengan cara memberikan penilaian dari 1 sampai 4, yang selanjutnya dihitung rata-ratanya dan disajikan dalam tabel. Hasil penelitian yaitu kepuasan dan loyalitas wisatawan yang mengunjungi destinasi wisata Pulau Harapan di Kepulauan Seribu Jakarta dengan skala penilaian 1 sampai 4 , diperoleh nilai rata-rata untuk kepuasan $=3.14$ (kategori puas), untuk loyalitas wisatawan diperoleh nilai rata-rata $=3.25$ (katagori loyal).
\end{abstract}

Kata Kunci : Kepuasan, Loyalitas, Destinasi Wisata

\begin{abstract}
The Thousand Islands Administrative District Government has supported the development of tourism on Pulau Kelapa Island in the Thousand Islands. This can be seen from the efforts of the government in providing facilities and facilities and infrastructure to support tourism to develop the Thousand Islands as a tourist destination. The purpose of this study is: To find out the satisfaction and loyalty of tourists who visit Harapan Island Tourism Destinations in the Thousand Islands, Jakarta. The research will be carried out by distributing questionnaires to 100 people (using the Slovin formula) who have visited the island of Hope in the Thousand Islands, Jakarta. The method of analysis is done by descriptive analysis, which is by describing or describing the results of research on the satisfaction and loyalty of tourists who visit the Coconut Island Tourism Destinations in the Thousand Islands Jakarta by giving an assessment of 1 to 4, which are then calculated on average and presented in the table. The results of the study are the satisfaction and loyalty of tourists visiting the Harapan Island tourist destination in the Thousand Islands Jakarta with a rating scale of 1 to 4, obtained an average value for satisfaction $=3.14$ ( satisfied category), for tourist loyalty obtained an average value $=3.25$ (category loyal).
\end{abstract}

Keywords: Satisfaction, Loyalty, Travel Destinations 


\section{PENDAHULUAN}

Pemerintah Kabupaten Administrasi Kepulauan Seribu telah mendukung pengembangan pariwisata di berbagai pulau yang ada di Kepulauan Seribu. Hal tersebut dapat dilihat dari usaha pemerintah dalam menyediakan fasilitas serta sarana dan prasarana penunjang pariwisata untuk mengembangkan Kepulauan Seribu sebagai daerah tujuan wisata.

Berdasarkan data dari Dinas Pariwisata dan Kebudayaan Kepulauan Seribu jumlah pengunjung pulau berpenduduk lebih banyak ( tahun 2015 sebanyak 96,06\% dan tahun 2016 sebanyak 84,8 \%) dibandingkan jumlah pengunjung ke pulau yang tidak berpenduduk. Lebih banyaknya pengunjung ke pulau yang berpenduduk dikarenakan pulau tersebut sudah lebih baik dari segi fasilitas, sarana dan prasarana, serta mudahnya transportasi menuju pulau tersebut. Selain itu harga penginapan di pulau yang berpenduduk lebih murah dibandingkan dengan pulau lainnya. Pulau Harapan merupakan pulau berpenduduk yang letaknya paling jauh dari daratan Jakarta dan dijadikan pengembangan daerah tujuan wisata.

Penelitian ini bertujuan untuk mengetahui kepuasan yang dirasakan wisatawan dan loyalitas wisatawan yang mengunjungi destinasi wisata Pulau Harapan di Kepulauan Seribu Jakarta.

Menurut Kotler (2017), Kepuasan yaitu perasaan senang atau kecewa seseorang berdasarkan hasil perbandingan antara kesannya terhadap kinerja (hasil) suatu produk dengan harapannya. Menurut Lovelock \& Wirtz (2011), Kepuasan adalah suatu sikap yang diputuskan berdasarkan pengalaman yang didapatkan. Sangat dibutuhkan penelitian untuk membuktikan ada atau tidaknya harapan sebelumnya yang merupakan bagian terpenting dalam kepuasan.

Dari beberapa pengertian kepuasan menurut beberapa ahli dapat disimpulkan pengertian kepuasan adalah perasaan senang atau puas dan kecewa atau tidak puas seseorang berdasrkan pengalaman yang didapatkannya setelah membandingkan antara harapan dan kenyataan yang telah dirasakan atau dialaminya.

Konsep loyalitas pelanggan banyak dikaitakan dengan perilaku (behavior) daripada dengan sikap, sehingga konsumen atau pelanggan yang loyal maka ia akan menunjukkan perilaku dalam pembelian ulang yang dapat dilihat dari pembelian dari waktu ke waktu (Griffin, 2005:5). Griffin juga menyatakan bahwa pelangan yang loyal akan memiliki prasangka yang spesifik mengenai apa yang akan dibelinya. Selain itu loyalitas juga menunjukkan kondisi dari durasi waktu tertentu dan mensyaratkan bahwa tindakan pembelian terjadi tidak kurang dari dua kali.

Kotler (2017:50) mengatakan bahwa konsumen yang loyal, tidak diukur dari berapa banyak dia membeli, tetapi dari berapa sering dia melakukan pembelian ulang, termasuk juga dalam merekomendasikan kepada orang lain untuk membeli. Lovelock, Wirtz, dan Chatterjee (2007:15) menyatakan bahwa loyalitas adalah kesediaan wisatawan untuk melanjutkan aktivitas terhadap suatu produk wisata dalam jangka waktu yang panjang dan melakukan aktivitas secara berulang, serta merekomedasikannya kepada temanteman secara sukarela.

Menurut Sunaryo (2013 : 159) kerangka pengembangan Destinasi Pariwi-sata paling tidak harus mencakup komponen-komponen utama sebagai berikut:

1. Objek dan Daya Tarik (Atractions) yang mencakup: daya tarik yang bisa berbasis utama pada kekayaan alam, budaya, maupun buatan/artificial, seperti event atau yang sering disebut sebagai minat khusus (special interent). 
2. Aksesibilitas (Accessibility), yang mencakup dukungan sistem transportasi yang meliputi: rute atau jalur transportasi, fasilitas terminal, bandara, pelabuhan dan moda transportasi yang lain.

3. Amenitas (Amenities), yang mencakup fasilitas penunjang dan pendukung wisata yang meliputi: akomodasi, rumah makan (food and baverage), retail, toko cinderamata, fasilitas penukaran uang, biro perjalanan, pusat informasi wisata, dan fasilitas kenyamanan lainnya.

4. Fasilitas pendukung (Ancillary Services) yaitu ketersediaan fasilitas pendukung yang digunakan oleh wisatawan, seperti bank, telekomunikasi, pos, rumah sakit, dan sebagainya.

5. Kelembagaan (Institutions) yaitu terkait dengan keberadaan dan peran masingmasing unsur dalam mendukung terlaksananya kegiatan pariwisata termasuk masyarakat setempat sebagai tuan rumah (host).

6. Keberhasilan suatu destinasi pariwisata dalam menarik kunjungan wisatawan tentunya tidak lepas dari kecermatan pengelola dalam memahami karakter dan ekspektasi pasar yang selanjutnya dijadikan acuan dalam pengembangan produk dan layanan serta fasilitas pendukung wisata yang terkait di dalamnya.

\section{METODE PENELITIAN}

Jenis data dan sumber data yang digunakan dalam penelitian ini dikelompokkan menjadi dua bagian yaitu :

1. Data Primer. Merupakan data yang diperoleh secara langsung dari obyek yang diteliti melalui riset lapangan secara langsung. Dalam penelitian ini, yang termasuk data primer yaitu data yang diperoleh dari hasil wawancara dengan pihak pengelola objek wisata dan hasil kuisioner yang diisi oleh wisatawan yang berkunjung ke Pulau Harapan di Kepulauan Seribu Jakarta

2. Data Sekunder. Merupakan data yang dikumpulkan, diolah dan diterbitkan oleh pihak lain yang diperoleh dari instansi terkait mengenai data jumlah pengunjung objek wisata di Kepulauan Seribu.

Pada penelitian ini yang menjadi populasi adalah pengunjung objek wisata ke Pulau Harapan di Kepulauan Seribu Jakarta yang menurut data dari Dinas Pariwisata dan Kebudayaan Kepulauan Seribu pada tahun 2016 berjumlah 86106 orang. Jadi polulasi dalam penelitian ini sebanyak 86106 orang pada tahun 2016. Karena keterbatasan tenaga, biaya, dan waktu yang tersedia, maka penelitian dilakukan terhadap sampel dengan penetuan ukuran atau jumlah sampel minimal dengan rumus Slovin yaitu :

$$
\mathrm{n}=\frac{\mathrm{N}}{1+\mathrm{N}(\mathrm{e})^{2}}=\frac{86106}{1+86106(0,1)^{2}}=100
$$

Dengan demikian jumlah sampel minimal sebanyak 100 orang, jadi dalam penelitian ini akan dilakukan penelitian terhadap 100 orang wisatawan. Untuk menentukan sampel terpilih akan digunakan purposive sampling yaitu memilih orang yang dianggap mewakili yaitu orang yang telah mengunjungi Pulau Harapan di Kepulauan Seribu Jakarta. 
Variabel yang diteliti perlu dibuat operasionalisasi variabel untuk mempermudah dalam mengukur variabel dan pembuatan kuesioner. Variabel penelitian disajikan pada Tabel 1.

Tabel 1. Operasionalisasi Variabel Penelitian

\begin{tabular}{|c|c|c|}
\hline Variabel & Dimensi & Indikator \\
\hline \multirow[t]{5}{*}{$\begin{array}{l}\text { Kepuasan setelah } \\
\text { mengunjungi destinasi } \\
\text { wisata }\end{array}$} & $\begin{array}{rr}a . & \text { Daya Tarik } \\
\text { Wisata } & \end{array}$ & $\begin{array}{l}\text { 1. Kepuasan } \\
\text { menikmati Keindahan pantai } \\
\text { 2. Ketersediaan fasilitas } \\
\text { permainan air }\end{array}$ \\
\hline & $\begin{array}{l}\text { b. Aksesibilitas dan } \\
\text { Transportasi }\end{array}$ & 3. Kepuasan selama di kapal \\
\hline & $\begin{array}{l}\text { c. Amenitas ( fasilitas } \\
\text { penunjang dan pendukung } \\
\text { wisata }\end{array}$ & $\begin{array}{l}\text { 4. Kepuasan di penginapan } \\
\text { 5. Kepuasan menikmati } \\
\text { makanan dan minuman }\end{array}$ \\
\hline & $d$. Fasilitas pendukung & $\begin{array}{l}\text { 6. Kepuasan atas jaringan } \\
\text { telekomunikasi } \\
\text { 7. Kepuasan Ketersediaan } \\
\text { Anjungan Tunai Mandiri (ATM) }\end{array}$ \\
\hline & e. Kelembagaan & $\begin{array}{l}\text { 8. Kepuasan atas keramahan } \\
\text { penduduk setempat }\end{array}$ \\
\hline \multirow[t]{3}{*}{ Loyalitas } & $\begin{array}{l}\text { a. Melakukan pembelian } \\
\text { ulang }\end{array}$ & $\begin{array}{l}\text { 1. Bersedia datang lagi ke } \\
\text { Pulau Harapan }\end{array}$ \\
\hline & b. Komitmen & $\begin{array}{l}\text { 2. Bersedia mengajak } \\
\text { teman/famili }\end{array}$ \\
\hline & c. Rekomendasi & $\begin{array}{l}\quad \text { 3. Bersedia } \\
\text { merekomendasikan kepada orang } \\
\text { lain untuk wisata ke Pulau } \\
\text { Harapan }\end{array}$ \\
\hline
\end{tabular}

Untuk mengetahui karakteristik wisatawan ke Pulau Harapan dilakukan dengan analisis deskriptif, yaitu dengan mendeskriptifkan atau menggambarkan tentang ciri-ciri wisatawan, yang selanjutnya disajikan dalam tabel yang dihitung rata-rata dan persentasenya. Untuk mengetahui pendapat wisatawan mengenai kepuasan dan loyalitas dilakukan dengan mendeskripsikan atau menggambarkan tentang hasil dari penelitian mengenai kepuasan dan loyalitas wisatawan dengan 4 pilihan jawaban yang diberi nilai dari 1 sampai 4 yang selanjutnya dihitung nilai rata-rata dari masing-masing pertanyaan dengan nilai dan kriteria disajikan pada Tabel 2. 
Tabel 2. Nilai, Nilai Rata-rata, dan Kriteria Mengenai Kepuasan dan Loyalitas Wisatawan Pulau Harapan

\begin{tabular}{|c|c|l|c|}
\hline Nilai & $\begin{array}{c}\text { Nilai Rata- } \\
\text { rata }\end{array}$ & \multicolumn{1}{|c|}{ Kepuasan } & Loyalitas \\
\hline 1 & $1,00-1,55$ & Sangat Tidak Puas & $\begin{array}{c}\text { Sangat Tidak } \\
\text { Loyal }\end{array}$ \\
\hline 2 & $1,56-2,55$ & Tidak Puas & Tidak Loyal \\
\hline 3 & $2,56-3,55$ & Puas & Loyal \\
\hline 4 & $3,56-4,00$ & Sangat Puas & Sangat Loyal \\
\hline
\end{tabular}

\section{HASIL DAN PEMBAHASAN}

\section{Kepuasan Wisatawan Pulau Harapan di Kepulauan Seribu Jakarta}

Pariwisata adalah berbagai macam kegiatan wisata dan didukung berbagai fasilitas serta layanan yang disediakan oleh masyarakat, pengusaha, dan pemerintah. Sedangkan wisata merupakan kegiatan perjalanan yang dilakukan oleh seseorang atau sekelompok orang dengan mengunjungi tempat tertentu untuk tujuan rekreasi, pengembangan pribadi, atau mempelajari keunikan daya tarik wisata yang dikunjungi, dalam jangka waktu sementara. Wisatawan yang datang ke Pulau Harapan umumnya bertujuan untuk rekreasi dengan menikmati keindahan pantai, umumnya wisatawan akan pergi ke beberapa pulau yang ada di sekitar Pulau Harapan terutama ke Pulau Perak, Pulau Dolpin, Pulau Bira, Pulau Gosong, dan Pulau lainnya.

Dalam mengukur kepuasan destinasi pariwisata pada penelitian ini digunakan 5 dimensi yaitu : 1. Daya Tarik wisata, 2. Aksesibilitas, 3. Amenitas, 4. Fasilitas pendukung, dan 5. Kelembagaan. Kepuasan yaitu Perasaan senang atau puas dan kecewa atau tidak puas berdasarkan pengalaman setelah membandingkan antara harapan dan kenyataan setelah mengunjungi destinasi wisata Pulau Harapan Kepulauan Seribu Jakarta. Pilihan jawaban untuk kuesioner mengenai kepuasan yaitu : 1) sangat tidak puas, 2) Tidak puas, 3) Puas, 4) Sangat puas. Hasil jawaban responden terhadap pertanyaan atau kuesioner yang diisi oleh 100 wisatawan, yang hasilnya sebagai berikut :

\section{Kepuasan Menikmati Keindahan Pantai Pulau Harapan}

Daya tarik wisata yang ada di Pulau Harapan yaitu keindahan pantai yang dihiasi dengan pohon mangrove, deretan pulau-pulau kecil yang ada di sekeliling Pulau Harapan, dan deretan perahu nelayan, dan kapal yang ada di dermaga sekitar Pulau Harapan.

Pulau Harapan di Kepulauan Seribu adalah pulau yang cocok bagi yang menyukai suasana sepi dan tidak bising karena pulau ini tidak banyak di kunjungi oleh wisatawan. Pulau harapan merupakan salah satu pulau yang berpenghuni di kepulauan seribu dan merupakan pulau yang berpenduduk. Wisatawan akan terkagum kagum melihat keindahan alam pantai yang begitu menawan dengan pantai yang biru membuat semua orang ingin langsung berenang. Biasanya wisatawan yang berkunjung ke Pulau Harapan selalu berkunjung ke Pulau Dolphin, dan Pulau Perak.

Pulau Dolphin adalah pulau tidak berpenghuni dan terlihat eksotis. Semua fasilitas disediakan langsung oleh alam. Indah, alami dan bersih. Keanekaragaman pesona bawah lautnya juga sungguh luar biasa. Pulau Dolphin ini merupakan pulau kecil yang 
menyediakan lahan untuk berkemah. Pulau ini merupakan spot camping tepi pantai terbaik yang berpasir putih dengan kontur pantai yang landai. Pulau Dolphin dikelilingi spot snorkeling dan lanskap pulau-pulau tak berpenghuni. Jika beruntung dapat menyaksikan nemo berenang di terumbu karang atau bahkan penyu.

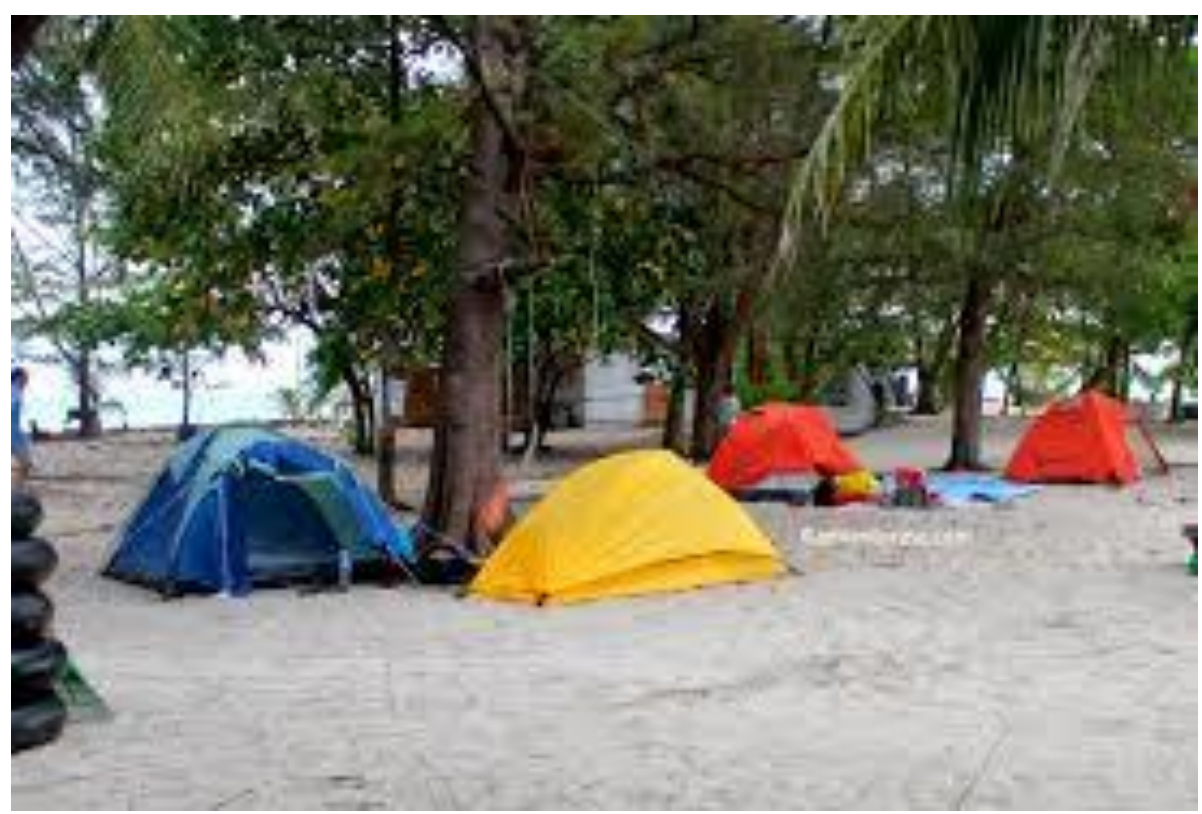

Gambar 1. Pulau Dolphin Biasa Digunakan untuk Camping

Pulau Perak juga adalah pulau yang tidak berpenghuni. Tapi tenang, Namun ada seorang penjaga pulau dan warung kecil yang siap memenuhi kebutuhan wisatawan. Pulau Perak sangat indah untuk dinikmati, wisatawan bisa merasakan sensasi 'private island' yaitu merupakan pulau dengan hamparan pasir putih dan lautnya yang tenang, wisatawan bisa melakukan snorkeling di sekitar Pulau Perak yang pasti akan mengasyikkan.

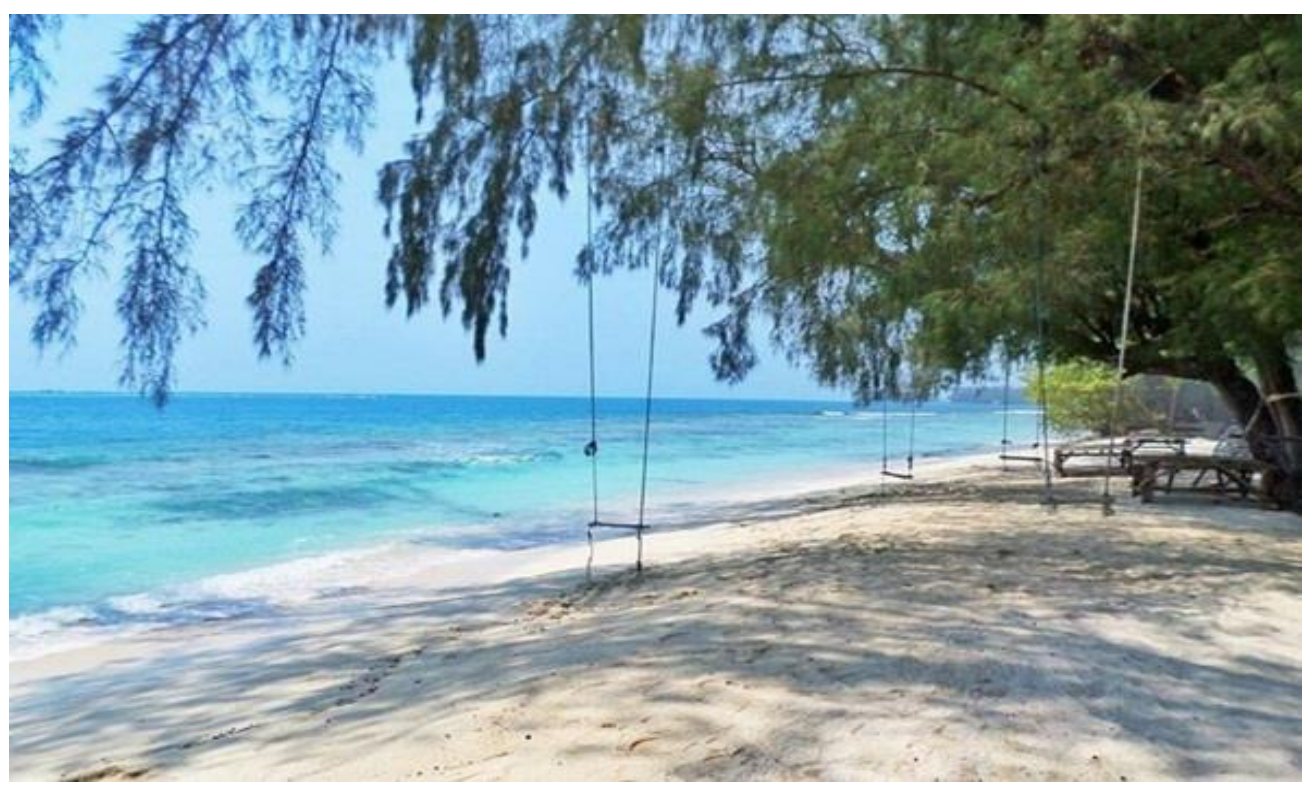

Gambar 2. Keindahan Pulau Perak 


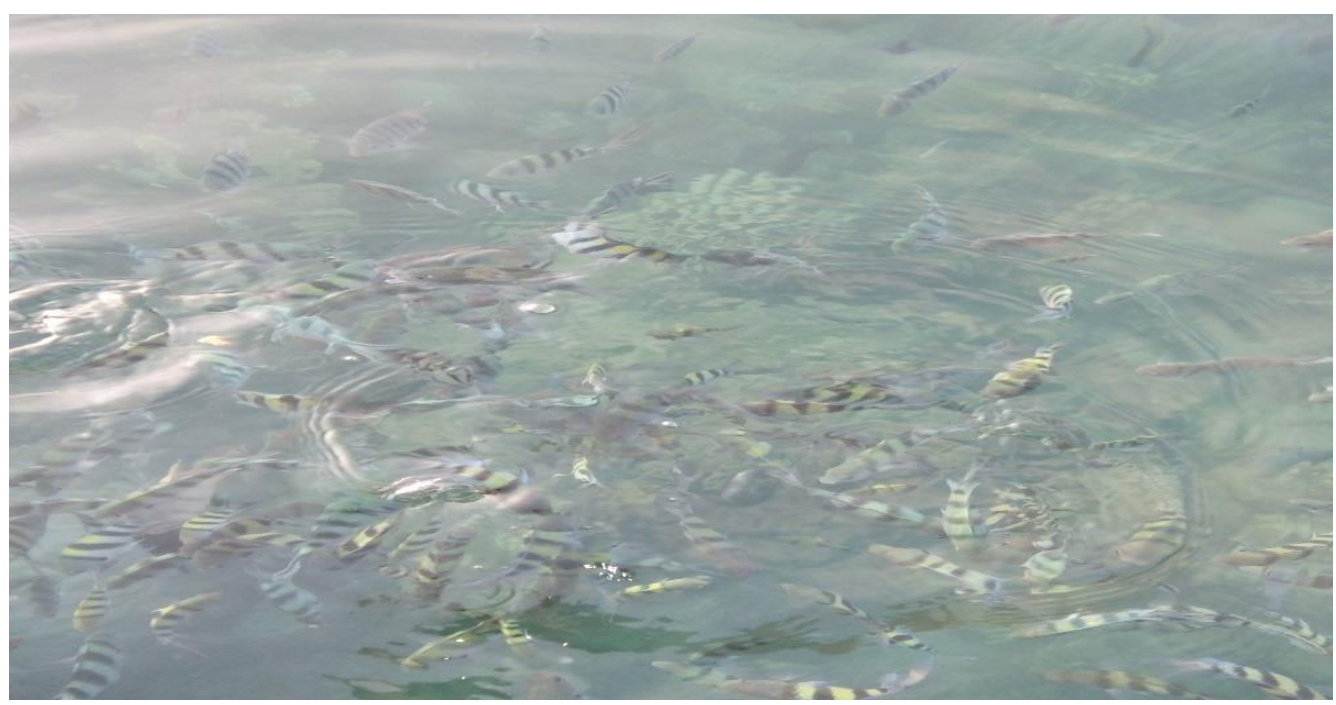

Gambar 3. Ikan yang ada di Perairan Sekitar Pulau Harapan

\section{Kepuasan Menikmati Fasilitas Permainan Air}

Wisatawan juga bisa menikmati permainan air seperti naik Donnut Boat, Banana Boat, Snorkling, berenang, dan memancing ikan. Wisatawan yang datang ke Pulau Harapan dengan tujuan memancing merasa sangat senang karena ikan di wilayah sekitar Pulau Harapan banyak, namun untuk mendapatkan ikan yang lebih banyak dan punya sensasi lain yang lebih seru kadang-kadang pergi ke pulau lain dengan menyewa perahu motor dengan ukuran lebar 2 sampai 3 meter dan panjang 6 sampai 8 meter.

Wisatawan datang ke Pulau Harapan selain menikmati keindahan alam pantai juga menikmati keindahan terumbu karang/wisata bawah air. Untuk menikmati keindahan terumbu karang/wisata bawah air wisatawan harus menyewa perahu motor kecil yang bisa muat sekitar 10 sampai 15 orang biasanya menuju pulau yang ada di sekitar Pulau Harapan. Menyewa perahu harus diboking satu perahu, tidak diberlakukan ongkos atau biaya per orang seperti yang berlaku di Pulau Untung Jawa. Ongkos sewa perahu dan peralatan snorkling sekitar Rp 700000 per perahu dengan jarak tempuh sekitar 30 menit dan lama snorkling sekitar 1 jam.

Biasanya ada beberapa spot yang dipilih untuk snorkeling di sekitar Pulau Harapan Kepulauan Seribu. Spot pertama adalah Pulau Genteng dengan terumbu karangnya yang indah, berlanjut ke Pulau Macan yang memiliki biota laut lebih beragam. Spot ketiga biasanya di Pulau Perak yang punya hamparan pasir putih nan lembut.

\section{Kepuasan Selama di Kapal}

Akses menuju Pulau Harapan karena merupakan pulau yang berpenghuni dan dengan jumlah penduduk banyak maka sangat mudah dijangkau melalui transportasi kapal laut yang sudah memadai, baik yang dimiliki masyarakat maupun pemerintah. Terdapat beberapa akses untuk menuju ke Pulau Kelapa dan Pulau Harapan, yaitu: 


\section{a. Dari Dermaga Marina Ancol}

Wisatawan yang akan berkunjung ke Pulau Kelapa atau Pulau Harapan bisa berangkat dari Dermaga Marina Ancol dengan menggunakan kapal cepat (speed boat) dengan lama perjalanan sekitar 90 menit ( 1,5 jam). Kapal akan berangkat jam 8.00 pagi, penumpang harus sudah berada di kapal paling lambat jam 7.30. Ongkos naik kapal cepat ini untuk menuju Pulau Kelapa atau Pulau Harapan sebesar Rp 190. 000,- per orang untuk sekali keberangkatan untuk hari Senin sampai hari Jumat, sedangkan untuk hari Sabtu, Minggu, dan hari libur Rp 235.00,- per orang.

\section{b. Dari Kali Adem}

Wisatawan yang akan berkunjung ke Pulau Kelapa atau Pulau Harapan bisa berangkat dari Dermaga Kali Adem dengan menggunakan kapal milik masyarakat dan milik Dinas Perhubungan, lama perjalanan 3 sampai 4 jam. Kapal akan berangkat jam 8.00 pagi, penumpang harus sudah berada di kapal paling lambat jam 7.30. Namun kalau penumpang banyak biasanya aka nada kapal yang diberangkatkan lagi. Harga Tiket yaitu $\mathrm{Rp} 55.000$,- $^{-}$dan retribusi peron sebesar $\mathrm{Rp} 2.000,-$ per penumpang.

\section{c. Dari Pelabuhan Sunda Kelapa}

Wisatawan yang akan berkunjung ke Pulau Kelapa atau Pulau Harapan bisa berangkat dari Dermaga Sunda Kelapa dengan menggunakan kapal Sabuk Nusantara 66 dengan lama perjalanan sekitar 5 jam. Kapal akan berangkat jam 8.00 pagi, penumpang harus sudah berada di kapal paling lambat jam 7.30. Ongkos naik kapal menuju Pulau Kelapa atau Pulau Harapan sebesar Rp 15.000,- (lima belas ribu rupiah) per orang.

\section{Kepuasan di Penginapan}

Keberadaan penginapan berupa homestay menjadi daya tarik tujuan wisata pada wisatawan dalam berkunjung. Menurut wisatawan keberadaan homestay memberikan keunikan tersendiri, karena homestay ini hanya berada di Pulau Seribu di pulau yang berpenduduk saja, sedangkan di pulau yang tidak berpenduduk penginapan yang ada berupa cottage atau resort. Keberadaan homestay membuat wisatawan berada pada lingkungan rumah yang ramah dan merasa dekat dengan penduduk lokal di Pulau Harapan. Wisatawan juga mengganggap penginapan tersebut layak karena penginapan disana berupa rumah yang dirawat oleh warga setempat, yang pada umumnya dilengkapi dengan fasilitas AC namun ada juga yang hanya ditengkapi dengan kipas angin.

Berwisata ke Pulau Harapan harus menginap karena lama perjalanan dari daratan Jakarta menuju Pulau Harapan yaitu antara 3 sampai 5 jam. Penginapan berupa rumah penduduk yang disewakan kepada wisatawan yang dilengkapi pendingin udara ( AC) atau lebih dikenal dengan intilah homestay banyak tersedia. Harga yang per kamar dengan fasilitas AC dan kamar mandi di dalam bisa ditempati 2 sampai 3 orang sekitar Rp 300 000 sampai Rp 400.000. Rumah dengan 2 kamar ada ruang tamu dilengkapi AC harga sekitar Rp 700.000 sampai Rp 800.000. Sedangkan Rumah dengan 3 kamar tidur ada ruang tamu dilengkapi AC harga sekitar Rp 1.000.000 sampai Rp 1.200.000.

\section{Kepuasan Menikmati Makanan dan Minuman}

Setelah sampai di daerah tujuan biasanya wisatawan memerlukan makanan dan minuman sebagai kebutuhan utama. Bagi wisatawan yang berwisata menggunakan jasa Tour and Travel umumnya biaya yang ditetapkan sudah termasuk kebutuhan makan, 
yaitu mendapat makan pagi atau sarapan, makan siang dan makan malam dengan menu biasanya makan pagi adalah nasi goring, sedangkan makan siang dan makan malam yaitu ikan laut, sayur dan sambal. Bagi yang berwisata tidak menggunakan jasa Tour and Travel tersedia makanan dan minuman di warung makan yang ada di Pulau Harapan.

\section{Kepuasan Terhadap Ketersediaan Jaringan Komunikasi}

Pada jaman sekarang komunikasi dengan keluarga, kerabat, dan sahabat sangat penting. Komunikasi yaitu biasa dilakukan melalui telepon, dan jaringan internet. Di Pulau Harapan jaringan telepon seluler dan jaringan internetsudah tersedia, sehingga wisatawan yang datang ke Pulau Harapan bisa berkomunikasi dengan menggunakan berbagai media sosial dengan pihak keluarga dan sahabat.

\section{Kepuasan Adanya Anjuangan Tunai Mandiri (ATM)}

Pada jaman sekarang biasanya orang bepergian tidak selalu membawa uang tunai, namun biasanya yang dibawa adalah kartu ATM. Hal tersebut karena membawa uang tunai dalam jumlah yang banyak sangat beresiko. Di Pulau Harapan mesin ATM yang ada hanya mesin ATM Bank Jakarta.

\section{Kepuasan Akan Keramahan Penduduk}

Kegiatan pariwisata di Pulau Harapan banyaak melibatkan masyarakat setempat, yaitu mulai dari yang menyediakan sarana transportasi (awak kapal), pemilik penginapan, dan para penjual makanan dan minuman. Agar wisatawan merasa puas dan sangat puas sehingga mereka mau berkunjung lagi, maka penduduk di Pulau Harapan sebaiknya sersikap sangat ramah kepada wisatawan.

Berdasarkan hasil penelitian mengenai indikator kepuasan yang dirasakan wisatawan yang mengunjungi destinasi wisata Pulau Harapan yang telah dijelaskan di atas, maka dapat dibuat rekapitulasinya yang disajikan pada Tabel 3.

Tabel 3. Rekapitulasi Kepuasan Wisatawan yang Mengunjungi Destinasi Wisata Pulau Harapan

\begin{tabular}{|c|c|r|c|}
\hline No & $\begin{array}{r}\text { Nilai } \\
\text { Rata-rata }\end{array}$ & Kriteria \\
\hline 1 & $\begin{array}{c}\text { Kepuasan Menikmati Keindahan Alam } \\
\text { Pantai }\end{array}$ & 3,56 & Sangat Puas \\
\hline 2 & $\begin{array}{l}\text { Kepuasan Menikmati Fasilitas } \\
\text { Permainan Air }\end{array}$ & 3,12 & Puas \\
\hline 3 & Kepuasan Selama di Kapal & 2,40 & Tidak Puas \\
\hline 4 & Kepuasan di Penginapan Muas & 3,28 & Puas \\
\hline 5 & $\begin{array}{l}\text { Kepuasan Menikmati Makanan dan } \\
\text { Minuman }\end{array}$ & 3,40 & Puas \\
\hline 6 & $\begin{array}{l}\text { Kepuasan Terhadap Ketersediaan } \\
\text { Jaringan Komunikasi }\end{array}$ & 3,42 & Puas \\
\hline 7 & $\begin{array}{l}\text { Kepuasan Adanya Anjungan Tunai } \\
\text { Mandiri (ATM) }\end{array}$ & 2,40 & Tidak Puas \\
\hline 8 & Kepuasan akan Keramahan Penduduk & 3,52 & Puas \\
\hline Rata-rata & $\mathbf{3 , 1 4}$ & Puas \\
\hline
\end{tabular}

Sumber : Data Primer diolah, 2019 
Berdasarkan Tabel 3 dapat dilihat bahwa rata-rata nilai Kepuasan Wisatawan yang Mengunjungi Destinasi Wisata Pulau Harapan paling tinggi dengan nilai rata-rata = 3,56 yaitu mengenai kepuasan menikmati keindahan alam pantai termasuk kategori sangat puas. Nilai rata-rata terendah yaitu mengenai kepuasan selama di kapal dan kepuasan atas keberadaan Anjungan Tunai Mandiri (ATM). Rendahnya kepuasan selama di kapal karena wisatawan merasa tidak nyaman karena penumpang sangat penuh, sehingga penumpang duduk berdesak-desakan. Rendahnya kepuasan atas keberadaan Anjungan Tunai Mandiri (ATM) karena mesin ATM yang ada hanya ATM Bank DKI Jakarta.

\section{Loyalitas Wisatawan yang Mengunjungi Destinasi Wisata Pulau Harapan}

Menurut Lovelock, Wirtz, dan Chatterjee (2007:15) dalam industri pariwisata loyalitas adalah kesediaan wisatawan untuk melanjutkan aktivitas terhadap suatu produk wisata dalam jangka waktu yang panjang dan melakukan aktivitas secara berulang, serta merekomedasikannya kepada teman-teman secara sukarela. Kotler (2017:50) mengatakan bahwa konsumen yang loyal, tidak diukur dari berapa banyak dia membeli, tetapi dari berapa sering dia melakukan pembelian ulang, termasuk juga dalam merekomendasikan kepada orang lain untuk membeli. Dengan demikian wisatawan yang loyal dapat diukur dari :

1. Bersedia datang lagi ke Pulau Harapan

2. Bersedia mengajak teman/family ke Pulau Harapan

3. Bersedia merekomendasikan kepada orang lain untuk wisata ke Pulau Harapan

Hasil penelitian mengenai masing-masing indikator untuk loyalitas wisatawan ke Pulau Harapan disajikan pada Tabel 4

Tabel 4. Loyalitas Wisatawan yang Mengunjungi Destinasi Wisata Pulau Harapan

\begin{tabular}{|c|l|r|c|}
\hline No & Indikator Loyalitas & $\begin{array}{r}\text { Nilai } \\
\text { Rata-rata }\end{array}$ & Kriteria \\
\hline 1 & Bersedia Datang Lagi ke Pulau Harapan & 3,16 & Loyal \\
\hline 2 & $\begin{array}{c}\text { Bersedia Mengajak Teman/family ke } \\
\text { Pulau Harapan }\end{array}$ & 3,24 & Loyal \\
\hline 3 & $\begin{array}{l}\text { Bersedia Merekomendasikan Kepada } \\
\text { Orang Lain }\end{array}$ & 3,36 & Loyal \\
\hline \multicolumn{2}{|l|}{ Rata-rata } & $\mathbf{3 , 2 5}$ & Loyal \\
\hline
\end{tabular}

Sumber : Data Primer diolah, 2019

Berdasarkan Tabel 4 dapat dilihat bahwa rata-rata nilai loyalitas Wisatawan yang Mengunjungi Destinasi Wisata Pulau Harapan yaitu 3,25 termasuk katagori loyal, indikator loyalitas paling tinggi yaitu mengenai bersedia merekomendasikan kepada orang lain dengan nilai rata-rata $=3,36$ termasuk kategori loyal. Nilai rata-rata terendah yaitu mengenai bersedia datang lagi ke Pulau Harapan dengan nilai rata-rata 3,16 termasuk katagori loyal. Rendahnya nilai rata-rata mengenai bersedia datang lagi ke Pulau Harapan karena jarak pulau Harapan dari daratan Jakarta sangat jauh, lama tempuh perjalanan naik kapal cukup lama, dan bagi yang tidak terbiasa perjalanan laut cukup melelahkan, sehingga diperlukan keberanian selama dalam perjalanan. Selain itu 
wisatawan ingin mendatangi pulau lainnya yang ada di Kepulauan Seribu selain Pulau Harapan.

\section{KESIMPULAN DAN SARAN}

\section{Kesimpulan}

1. Karakteristik wisatawan yang datang ke Pulau Untung Jawa Kepulauan Seribu Jakarta yaitu : 1) Laki-laki 67 persen dan perempuan 33 persen, 2) Paling banyak (83 persen) berusia 17 tahun sampai 30 tahun, 3) Paling banyak (52 persen) berpendidikan D3/S1/S2, 4) Paling banyak (87 persen) pelajar/mahasiswa dan pegawai swasta, 5) Paling banyak (70 persen) berpendapatan kurang atau sama dengan Rp 3.000.000 per bulan, 6) Paling banyak (61 persen) berkunjung 1 kali , 7) Paling banyak (89 persen ) berencana akan datang lagi, 9) Paling banyak (85 persen) pengaturan perjalanan menggunakan Tour and Travel (Biro Perjalanan).

2. Kepuasan wisatawan yang mengunjungi destinasi wisata Pulau Harapan di Kepulauan Seribu Jakarta dengan skala penilaian 1 sampai 4, diperoleh nilai rata-rata $=3.14$ (kategori puas). Indikator kepuasan wisatawan yang memperoleh nilai lebih besar dari rata-rata yaitu : 1) Kepuasan menikmati keindahan alam, 2) Kepuasan di penginapan, 3) Kepuasan menikmati makanan dan minuman, 4) Kepuasan terhadap ketersediaan jaringan komunikasi, dan 5) Kepuasan akan keramahan penduduk. Indikator kepuasan wisatawan yang memperoleh nilai lebih kecil dari rata-rata yaitu : 1) Kepuasan menikmati fasilitas permainan air, 2) Kepuasan selama di kapal, 3) Kepuasan adanya Anjungan Tunai Mandiri (ATM.

3. 4. Loyalitas wisatawan yang mengunjungi destinasi wisata Pulau Harapan di Kepulauan Seribu Jakarta dengan skala penilaian 1 sampai 4, diperoleh nilai rata-rata $=3.25$ (katagori loyal). Indikator loyalitas wisatawan yang memperoleh nilai lebih besar dari rata-rata yaitu : 1) Bersedia merekomendasikan kepada orang lain untuk berwisata ke Pulau Harapan. Indikator loyalitas wisatawan yang memperoleh nilai lebih kecil dari rata-rata yaitu : 1) Bersedia datang lagi ke Pulau Harapan, dan 2) Bersedia mengajak teman/family ke Pulau Harapan.

\section{Saran}

1. Pihak pemerintah, masyarakat, dan pengelola kawasan wisata Pulau Harapan hendaknya secara bersama-sama berusaha untuk mempertahankan dan meningkatkan kualitas destinasi wisata yang ada di Pulau Harapan dan sekitarnya agar kepuasan dan loyalitas wisatawan meningkat.

2. Untuk meningkatkan kepuasan wisatawan selama di kapal, sebaiknya jumlah penumpang tidak melebihi kapasitas kapal, juga sebaiknya untuk pembelian tiket kapal bisa dilakukan secara online, agar penumpang mempunyai kepastian mendapat tempat duduk.

3. Untuk meningkatkan kepuasan wisatawan akan keberadaan Anjungan Tunai Mandiri, sebaiknya mesin ATM yang ada harus link dengan Bank lainnya, sehingga pengguna bank lain bisa mengambil uang di mesin ATM Bank DKI yang ada di Pulau Harapan. 


\section{DAFTAR PUSTAKA}

Basiya dan Rozak. (2012). Kualitas Daya Tarik Wisata, Kepuasan, dan Niat Kunjungan Kembali Wisatawan Mancanegara di Jawa tengah. Jurnal Dinamika Kepariwisataan, Vol. XI No.2, p. 1-12.

Kirom, Novita Rifaul. (2016). Faktor-faktor Penentu Data tarik Wisata Budaya dan Pengaruh-nya Terhadap Kepuasan Wisatawan. Jurnal Pendidikan, Vol. I No. 3, p $536-546$.

Kotler Philip, dan Keller, Kevin Lane. (2017). Manajemen Pemasaran Jilid 1. Penerbit Erlangga. Jakarta.

Lovelock, Cristhoper. (2014). Manajemen Pemasaran Jasa. PT. INDEKS. Jakarta.

Marpaung, Happy dan Bahar, Herman. (2015). Pengantar Pariwisata. Penerbit Alfabeta. Bandung.

Meng, Fang.,Tepanon, Yodmanee., dan Uysal, Muzaffer. (2006). Measuring Tourist Satisfaction by Attribute and Motivation: The Case of Nature Based Resort. Journal of Vacation Marketing. Vol. 8 No.2, pp. 263-272.

Mill, Robert Christie, Alih Bahasa Sastro Tribudi. (2015). Tourism The international Business, Edisi Bahasa Indonesia. Penerbit PT Raja Grafindo Persada. Jakarta.

Morena, A, and Amelung, B. (2009). "Climate change and tourist comfort on Europe's beaches in summer: a reasseessment', Coastal Management, 37:550-568.

Mulyadi. (2015). Daya Tarik Wisata Buku 1. Salemba Empat. Jakarta.

Pendit, Nyoman S. (2010). Pengantar Ilmu Pariwisata. Pradnya Paramita. Jakarta.

Razak, Abdur dan Suprihardjo. (2013). Pengembangan Kawasan Wisata Terpadu Kepulauan Seribu. Institut Teknologi Sepuluh November. Surabaya.

Valle, Patricia, Guerreiro M., Mondes J., dan Silva J. (2011). The cultural offer as a tourist productin coastal destinations: The Case of Algarve, Portugal. Tourism and Hospitality Research, Vol. 11, pp. 233-247. 